\title{
Role-play in English Language Teaching
}

\author{
Feng Liu \& Yun Ding \\ School of Foreign Languages, Qingdao University of Science and Technology \\ Qingdao 266061, China \\ Tel: 86-532-8895-8959Ｅ-mail: liufeng7079@163.com
}

\begin{abstract}
Role-play is an effective technique to animate the teaching and learning atmosphere, arouse the interests of learners, and make the language acquisition impressive. So this research will mainly focus on how to apply it successfully and take the most advantage of it in English class. The outcome shows there are four crucial factors for its success: the topic chosen should be real and relevant; the teacher need 'feed-in' the appropriate language; correct errors in a proper way; some of teachers role are facilitator, spectator or participant. Incorporating role-play into the classroom adds variety, a change of pace and opportunities for a lot of language production and also a lot of fun!
\end{abstract}

Keywords: Role-play, Procedure, Feed-in

The main elements of Communicative Approach usually appear as three steps in classroom teaching: 1) presentation 2) practices 3) production. Applied to the third period, one of the effective practice is role-play, which emphasizes much on the comprehensively performance of the target language. While many researchers proved this means to be useful, many second language teachers still address to researchers: how to take most advantage of role-play and how to make a balance between it and the normal presentation of class room teaching? The research followed is an attempt to answer such questions by analyzing several related researches and some empirical evidence.

\section{Related research}

From the discussion of communicative teaching methodology, we can find that the function of language is not elicited from the forms of language, but its obligatory contexts .the contexts may be various; however, the forms of contexts still have some regular patterns to follow. D.Wilkins (1976) thus raised the notional syllabuses, which arranged teaching program mostly on the basis of contexts instead of being limited by the forms of sentences .to apply to the teaching contents to the desire of language application, communication becomes a widely used technique. According to it, Wilkins put forward the issue of role-play, which is actually an imitation the reality the students are required to speak properly in line with the contexts and their "roles". The whole procedure is as follows:

When organizing the practice of role-play, the teacher must provide a context and several roles for students to prepare and then perform in the class. The performance can be developed by several groups. When one is performing, the other students are audience and discuss its advantages and disadvantages afterward the discussion itself is also a kind of practice.

Empirical evidence derived from Wilkins' research and theories proved that role-play is an effective technique to animate the teaching and learning atmosphere, arouse the interests of learners, and make the language acquisition impressive.

Wilkins had proposed the general figures and theories for role-play, while some further researches were applied for this subject by the other researchers; more problems were thus raised to be solved afterwards.

Fraser, Rintell, and Walters (1980) proffer role-play as a useful means to study learners' pragmatic competence. Therefore, many contextual features are important in determining how a speaker will behave in a role-play; the speech act can be kept constant while the contextual features are varied. Many dimensions of a learner's pragmatic competence may be explored in this way in Fraser, Rintell and Walter's procedure; they also used role-plays with puppets when the subjects have been children.

From the two theoretical and empirical studies, we can get general concepts of role-play. Some further and more concise issues may be raised by the research as follows: 
The purpose of role-play that applies to practical usage in communication demands the flexibility of participants' words, generally speaking, the more approximately the activity access to reality, the more interests students will take in .so the choice of roles and contexts become very important. When teachers design a role-play, they must take students' ages and experience into consideration.

To sum up, the studies recited above presented the general research for role-play and affirmed the positive effect of role-play, which is proved to be useful in communicative teaching method. The lack of findings on this subject may be due to the fact that they did not give particular illustration for the regulation of the relationship between the teaching roles and learning roles. In this activity, students obviously played a center role. However, teachers should be a surveyor and control the whole situation in order to make class going on smoothly. And how can teacher control the procedure successfully? And how should teachers do when some negative things appear? My proposed study will try to provide some empirical evidence for solving such problems.

\section{Methodology}

\subsection{Research questions}

The proposed study addresses the following research questions.

1). In the procedure of role-play, how will the teachers do if the situation is "out of control"?

2). Shall the errors made by students be corrected in time?

3). If students discuss in native language without being aware of it, shall teachers correct him or not?

\subsection{Method}

The subjects of this study would be 30 Chinese freshmen learning English as a foreign language. They belong to one whole class.

The experiment would take two 50-minutes classes. During the procedure, the students would be divided into ten groups, each one including three students.

Each group would be given a topic. In order to make a comparison, every two groups will share the same one.

For the first class, teacher will take 10 minutes to explain the rules for this activity and make the previous work such as dividing the students into different groups and distribute topics to each group. Students thus will get information about the activity but not be told the experimental purpose of this experiment. And then they would have 15-20 minutes to prepare.

For the rest of the time, except for the break, each group has 5 minutes to present themselves in front of the class. When one is performing, the others would watch and record their comments for the player's advantages and disadvantages.

After that the last twenty minutes would be taken for discussion. From the discussion, both the teacher and the students would get an impressive comparison for each counterpart groups.

\subsection{Proposed procedure}

The practice of students' performance actually took 60 minutes .so there were thirty minutes left for the discussion. Generally speaking, this experiment gets its anticipated outcomes.

Topics given to the students were as below:

Situation one: Several freshmen are talking about college life and their majors. All of them are unsatisfied with their major to some extent.

Situation Two: John, one of your classmates, has been sick in hospital for quite some time. Now he is going to be back to school. You and your partners are talking about giving him some help with his missed study.

Situation three: you and your partner are from different parts of China. You are talking about the difference between your hometown and your university.

Situation four: shopping

A finds a pair of jeans whose design and color are exactly to his/her taste. A likes it very much but thinks it's too expensive. So A bargains with B, the salesperson, hoping to get some discount on the price.

The four topics are familiar to young students' life experience and have little limitation for speakers' words. Students could bring into full play of themselves with their own knowledge and experience .So the whole class went successfully. 


\section{Results}

\subsection{Vocabulary}

From the performance, students consciously applied the vocabulary from the presentation of new lessons . The effect of memorization and application of new words is proved better than single practice of recitation.

Almost 21 students (70\%) applied the new vocabulary freely during the procedure. As for the four topics, they are real and relevant to the students' life and all provide enough flexibility for students to imagine.

Occasionally, they would rely on Chinese to express some difficult meaning.

\subsection{Grammar}

The students avoided the limit of "formal speech "by taking lifelike forms in their conversation, e.g. elliptical sentences, repetition, exclamatory sentences, etc.

Some errors occasionally occurred. Those serious grammatical errors were corrected by the teacher immediately or by the students in the afterward discussion. Some slips of tongue were neglected while the speaker himself was aware of it.

\subsection{Communicative purpose}

Without rigid limit of word application, students had much space to bring their imagination and intelligence into full play. About $80 \%$ (24 students) can communicate freely and fluently in English in this way. However, the accuracy of their speaking needs to be improved. Here the accuracy does not only mean using grammars and vocabulary correctly without errors, but also refers to the "property of language ", which means to speak appropriately according to different time, places and situations.

\subsection{Teaching procedure}

During the whole procedure, there is no situation out of control occurred .all students throw themselves into their "roles", fusing the ideas, emotions and languages all together.

After the performance, the discussion went on with high enthusiasm. They made poignant comments on each other's performance and declared that they benefit a lot from others' presentation. Students also put forward some creative suggestions for this kind of practice. Those would be discussed in the following part.

\section{Suggestions}

\subsection{Prepare for success}

At the first period, the teacher should be brief and to the point so that the students would have more time to perform. Also, try to keep the topic real and relevant and the roles you ask students to play as real to life as possible. Try to think through the language the students will need and make sure this language has been presented. Students may need the extra support of having the language on the board. When the role-play began the students felt 'armed' with the appropriate language. At higher levels the students will not need so much support with the language but they will need time to 'get into' the role. Furthermore, the teacher should create a comfortable atmosphere so that the students wouldn't feel nervous and pressed

\subsection{Feed-in language}

As students practice the role-play they might find that they are stuck for words and phrases. In the practice stage the teacher has a chance to 'feed-in' the appropriate language. This may need the teacher to act as a sort of 'walking dictionary', monitoring the class and offering assistance as and when necessary. If you are not happy doing this and you feel that the process of finding the new language should offer more student autonomy, you could have 'time-out' after the practice stage for students to use dictionaries to look up what they need. Feeding-in the language students need is fundamental. By doing so, they will learn new vocabulary and structure in a natural and memorable environment. It is a chance to use real and natural language.

\subsection{Error Correction}

There are many ways to correct mistakes when using role-play. It is rarely appropriate for the teacher to jump in and correct every mistake. This could be incredibly de-motivating! Some students do like to be corrected straight after a role-play activity, while the language is still fresh in their minds. Sentences with errors can be written on the board for the group to correct together.

Self-correction - If you have the equipment to record the role-plays either on audiocassette or on video, students can be given the opportunity to listen to the dialogue again and reflect on the language used. They may find it easy to spot their own mistakes.

Peer-correction - Fellow students may be able to correct some mistakes made by their peers. Students could be asked to listen out for both great bits of language they'd like to use themselves, and some mistakes they hear. Be careful to keep 
peer-correction a positive and profitable experience for all involved.

Making a note of common mistakes yourself and dealing with them in future classes ensures that the students don't lose motivation by being corrected on the spot or straight after the role-play. Negotiate with students and ask them how they would like to be corrected

\subsection{The role of the teacher}

Some of the possible teacher roles are: Facilitator - students may need new language to be 'fed' in by the teacher. If rehearsal time is appropriate the feeding in of new language should take place at this stage. Spectator - The teacher watches the role-play and offers comments and advice at the end. Participant - It is sometimes appropriate to get involved and take part in the role-play yourself.

To sum up, incorporating role-play into the classroom adds variety, a change of pace and opportunities for a lot of language production and also a lot of fun! It can be an integral part of the class and not a 'one-off' event. It's fun and motivating; quieter students get the chance to express themselves in a more forthright way; the world of the classroom is broadened to include the outside world - thus offering a much wider range of language opportunities. In addition to these reasons, students who will at some point travel to an English speaking country are given a chance to rehearse their English in a safe environment. Real situations can be created and students can benefit from the practice. Mistakes can be made with no drastic consequences.

\section{References}

D. A. Wilkins. (1976). Notional Syllabuses. London, OUP.

Fraser, B., E. Rintell, \& J. Walters. (1980). An Approach to Conducting Research on the Acquisition of Pragmatic Competence in a Second Language. In D. Larsen-Freeman (Ed.), Discourse Analysis in Second Language Research (pp. 75-91). Rowley, MA: Newbury House.

H. G. Widdowson. (1984). Explorations in Applied Linguistics. London: OUP.

Harmer, J. (1991). The Practice of English Language Teaching. Longman.

Johnson, K \& K. (1981). Morrow. Communication in the Classroom. Longman. 